\title{
CHARACTERIZATION AND DEWATERING OF FLOTATION TECHNOLOGICAL TAILINGS
}

\author{
I. Grigorova and I. Nishkov ${ }^{\#}$
}

University of Mining and Geology “St. Ivan Rilski”, Faculty of Mines, Department of Mineral Processing and Recycling, 1700 Sofia, Bulgaria

(Received: January 9, 2014; Accepted: May 27, 2014)

\begin{abstract}
The treatment of flotation tailings is today a subject of interest in mineral processing because of the potential of wasted materials as an actual mineral resource and because of environmental reasons. Decantation ponds are found at almost every mine in the world. They are large earth fill dams containing the residue of the milling process to extract metals from mined ores. Traditional wet tailings disposal has been problematic due to the risk of ground water contamination and the difficulty in rehabilitating storage sites. Tailings dams are at risk of failure due to leakage, instability, liquefaction, and poor design. In the last few years the use of paste technology in the disposal of mine tailings is increasingly studied as an option to conventional tailings dams.

The Lucky Invest Concentrator is located in the Eastern Rhodopes Mountain of Bulgaria. Since 1959 lead-zinc ores are dressed. Finally, during the flotation cycle lead and zinc concentrates are produced. The final technological processing waste precipitates in tailing pond.

Research and development program has started to established opportunities to obtain dry deposit of the ore processing residue and analyses the feature of new tailing disposal method. The tailings particle size distributions and chemical compositions were determined. The data from laboratory and pilot scale tests clearly illustrate that there are the possibilities to obtaine lead-zinc dewatered tailings. The experimental results show that new cyclone modifications have a potential in dewatering technology of flotation tailings. It appears that dewatering cyclones can be an approach on new tailings pond elimination technology.
\end{abstract}

Key words: tailings, dewatering, hydrocyclone, deposition method.

\section{Introduction}

The mining industry generates large amounts of various solid and liquid wastes that can have negative impacts on the environment by changing the landscape, altering water tables, disrupting the local ecology, generating serious air and water pollution, and permanently degrading large areas of land. To prevent this from occurring it is important that there is wise management of every aspect of its operations using best applicable techniques [1].

\#Corresponding author: inishkov@gmail.com
The treatment and disposal of tailings pose enormous challenges that require a multidisciplinary study approach [2-4].

Traditional wet tailings disposal has been problematic due to the risk of ground water contamination and the difficulty in rehabilitating storage sites. Conventional slurry tailings dams are at risk of failure due to leakage, instability, liquefaction, and poor design [5, 6]. Since 1960, there have been 77 major geotechnical instabilities of tailings dams worldwide, resulting in at least 471 human deaths, serious economical impacts, and untold environmental damage [7]. 
In recent years, new approaches and technologies have been developed. These have significantly reduced dam failures and their subsequent environmental hazards and enabled mine operations to minimize wastes $[8,9]$. A common element of these techniques is that the tailings are thickened or dewatered prior to final disposal in dry form.

Dry disposal using thickened, paste, or filtered tailings offer the major advantages of improved water and reagent recovery and decreased in situ tailings volumes [10-12].

The methods used to dispose of tailings have developed due to environmental pressures, changing milling practice, and realization of profitable applications. In recent years, there is an increasing trend to make the tailings a useful material. Surface disposition of mine tailings in paste form is a new disposal technique. Dewatering changes the tailings' state from a low-viscosity fluid to a paste, there by accelerating the consolidation process and increasing the stability of the deposited stack. Paste is the term given to a mixture of solids and water such that, when left to stand idle, the bleed water is negligible. Hence, this new deposition method eliminates the need for a tailings pond [13].

The lead-zinc ores are dressed in Lucky Invest Concentrator in Bulgaria. These ores are characterized with variable and complex mineral and physical composition. Due to this fact, a selective flotation circuit was established. Finally, during the flotation cycle lead and zinc concentrates are produced and the final technological waste is precipitated in tailing pond.

This work proposes to focus on dewatering process of flotation tailings using dewatering hydrocyclones. The idea is to transform the final technological tails of Lucky Invest Concentrator into paste tailings and to replace traditionally tailing pond with surface disposal.

\section{Experimental}

\subsection{Technological tails characterization}

Monitoring of the final technological waste of Lucky Invest Concentrator was carried out. Periodic sampling, sample treatment, an average sample and relevant samples analysis were studied.

Monitoring methodology includes:

- Every 30 minutes cross-flow intersection sampling;

- Slurry flow rate determination;

- Determination of solids in the slurry;

- Pooling and drying of the samples at $105^{0} \mathrm{C}$;

- Homogenization and taking an average sample for the analysis;

- Particle size distribution and chemical analysis.

Particle size distribution of the sample was determined by micro-precision wet sieving $(0.400 \mathrm{~mm} ; 0.200 \mathrm{~mm} ; 0.100 \mathrm{~mm} ; 0.063 \mathrm{~mm}$; $0.056 \mathrm{~mm}$ ) using vibratory sieve shaker Analysete 3, Fritsch.

Particle size distribution of the samples with particle size less than $0.045 \mathrm{~mm}$ was obtained by Laser Particle Sizer Analysette 22, Fritsch.

Chemical analysis includes a complete silicate analysis and determination of lead, zinc and copper was determined by using AES-ICP and XRF.

\subsection{Dewatering laboratory tests}

Dewatering tests of the technological waste were performed with laboratory prototype dewatering separator Linatex HK40, production of Weir Minerals Company (Fig. 1).

The use of hydrocyclones in the thickening of tailings could result in several benefits as compared to dewatering in a conventional 
thickener. The advantages of the hydrocyclone system include lower capital expenditure, smaller footprint, and portability. Hydrocyclones have not been widely used for thickening of fine tailings due to the difficulty in producing clear overflow.

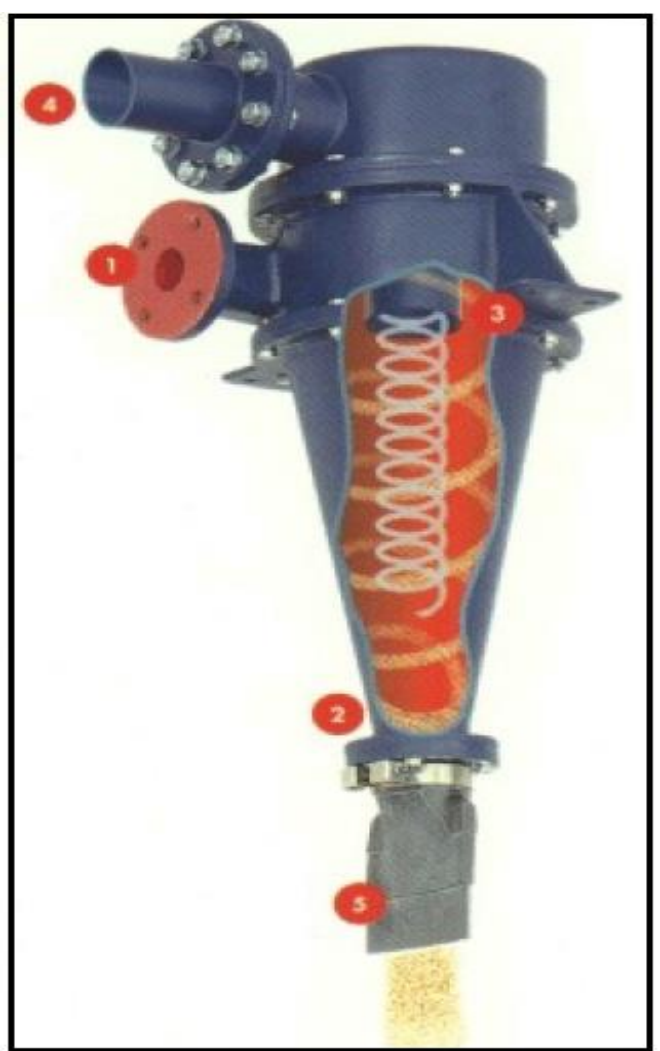

Figure 1. Linatex Separator Operation

The Linatex Separator is based on the same two forces as a conventional hydrocyclone: centrifugal and gravitational force. These forces are usually created by a centrifugal pump generating a force many times that of gravity. The material is fed to the Separator by way of a tangential entry (1) which imparts a rotational effect to the slurry, with the resulting centrifugal force causing those particles of higher density or bigger to be pushed against the inside surface of the Separator. As a result of the continuing feed of material and the inverted cone shape of the
Separator, these separated particles gravitate to the spigot (2), as in a conventional hydrocyclone.

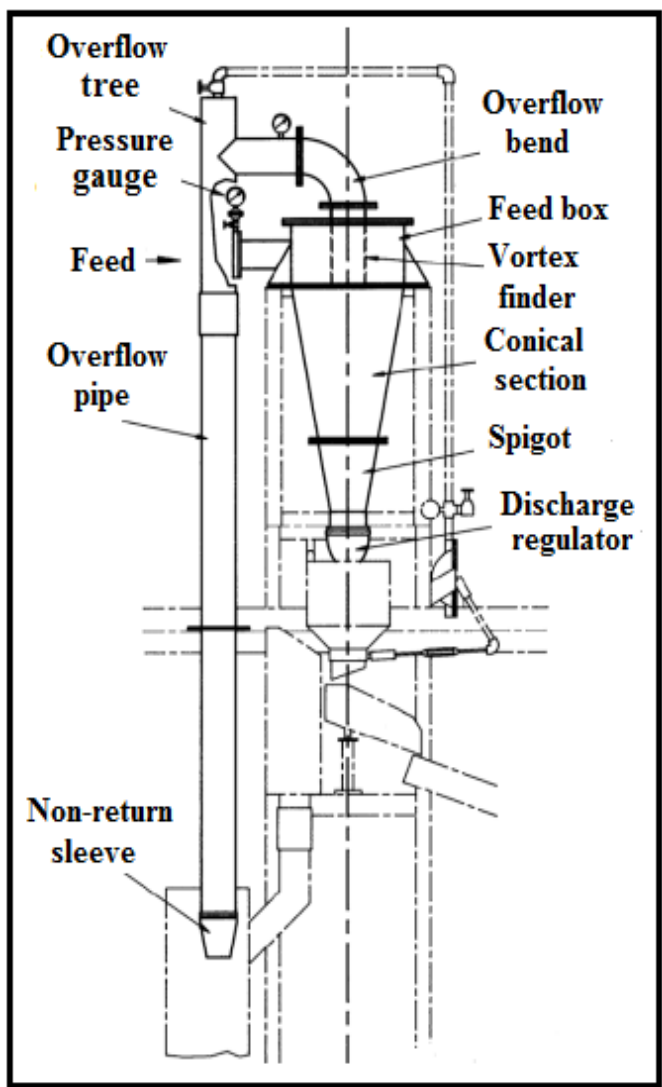

Figure 2. Linatex HK Separator

The water and fines pass upwards through the vortex finder (3) into the overflow, and are discharged away through the overflow pipe (4). The key to the success of the Linatex Separator lies in the discharge regulator (fishtail) (5), which is fitted below the spigot on the underflow.

An extended overflow pipe induces a syphon effect, which in turn creates a vacuum at the underflow of the Separator. This vacuum is sufficient to hold the Linatex discharge regulator closed thus trapping the majority of the water which are discharged via the overflow. When the weight of the solids 
inside the Separator is sufficient to overcome the vacuum, the discharge regulator is forced open and allows discharge of the solids.

This control of the material reporting to the underflow results in a much higher underflow density than is obtainable using a hydrocyclone. The vacuum in the Separator, and hence the density of the underflow material, is controlled by an air-bleed valve assembly mounted on the overflow pipe, which allows the syphon effect to be regulated.

The Linatex HK Separator (Fig. 2) comprises a feed box with a tangential entry. Below this is a cone terminating in a spigot fitted with a discharge regulator. Above the feed box is a plate which supports the vortex finder. Above the plate is an overflow bend providing an outlet. The overflow pipework leads from the outlet to a point about $2 \mathrm{~m}$ below the discharge regulator.

When in operation the overflow pipework acts as a syphon creating a negative pressure in the separator, this holds the discharge regulator closed (Fig. 3a) unless solids are present when it is opened by the weight of the solids themselves (Fig. 3b). The correct operation of the discharge regulator is dependant on the maintenance of the negative pressure in the separator created by the syphon effect of the overflow pipework.

Process flowsheet for laboratory tests is given on the Figure 4. The process flowsheet includes Linatex HK 40, self-balancing sump and tree sampling points - feed, overflow and underflow products. The cyclone overflow and underflow are returned to the sump to assure constant cyclone feed during the test.

The laboratory tests with Linatex HK40 are carried out at the following conditions: Feed flow rate $-14 \mathrm{~m}^{3} / \mathrm{h}$ and pressure $-\mathrm{P}=$ 1.5 bar. The laboratory prototype Linatex HK40 has the follow main dimensions: Body diameter $-\mathrm{D}=152 \mathrm{~mm}$, Inlet diameter $-\mathrm{D}_{\mathrm{i}}=$ $35 \mathrm{~mm}$ and Overflow diameter $\mathrm{D}_{\mathrm{o}}=51 \mathrm{~mm}$.

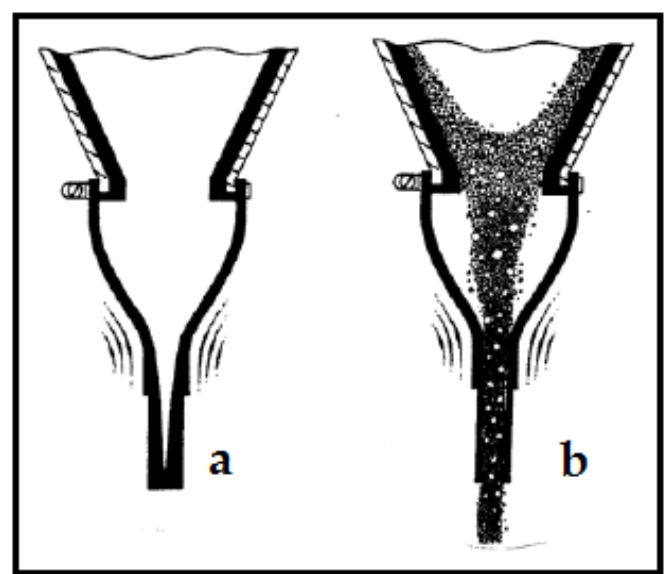

Figure 3. The action of discharge regulator underflow

a - discharge regulator closed; b discharge regulator opened

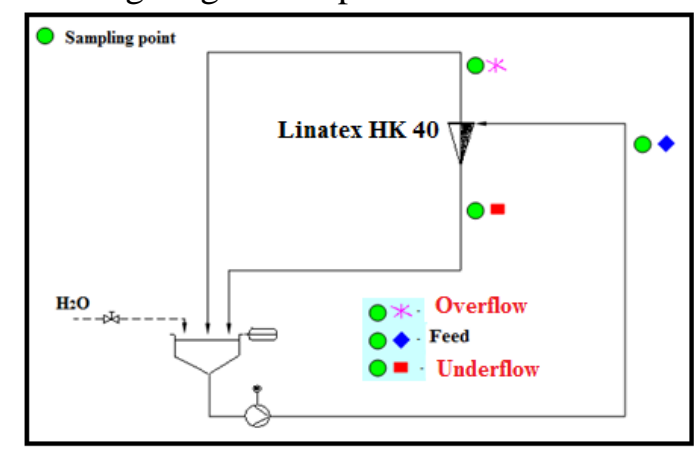

Figure 4. Process flowsheet for laboratory tests

The laboratory tests are conducted at different positions of siphon control valve:

- Closed air-bleed valve of overflow pipe;

- $30 \%$ opened air-bleed valve of overflow pipe;

- $50 \%$ opened air-bleed valve of overflow pipe.

\subsection{Pilot tests}

The pilot tests have been conducted with a separator Linatex HK 80 production of Weir Minerals Company and dewatering hydrocyclone Krebs gMAX - model gMAX20-SSC production of FLSmidth 
Company. All tests were carried out with closed air-bleed valve of overflow pipe.

The pilot tests with Linatex HK80 were performed at the following conditions: Feed flow rate $-55 \mathrm{~m}^{3} / \mathrm{h}$ and pressure $-\mathrm{P}=1.3 \mathrm{bar}$.

Linatex HK 80 has the follow main dimensions: Body diameter $-\mathrm{D}=381 \mathrm{~mm}$, Inlet diameter $-D_{\mathrm{i}}=80 \mathrm{~mm}$, Overflow diameter $-\mathrm{D}_{\mathrm{o}}=114 \mathrm{~mm}$, Underflow diameter - $\mathrm{D}_{\mathrm{u}}=70 \mathrm{~mm}$, Hydrocyclone length - L = $1115 \mathrm{~mm}$, Length overflow nozzle $-1=280$ $\mathrm{mm}$ and angle of conic part $-\alpha=10^{\circ}$.

In recent years FLSmidth has developed new Krebs gMAX hydrocyclone design with progressively increasing conical shape for finer and sharper separation and new inlet head for minimized wear.

Optimum cyclone performance relies on minimizing turbulence while maximizing tangential velocity. The new gMAX ${ }^{\circledR}$ cyclone focuses on these two important cyclone factors, significantly advancing cyclone performance. To achieve the two design criteria, the $\operatorname{gMAX}^{\circledR}$ incorporates performance-enhancing improvements to the inlet head, cylinder section, cones, and apex.

The Krebs gMAX ${ }^{\circledR}$ inlet has improved upon the Krebs involute feed inlet that had been the state-of - the-art in hydrocyclones for over 40 years. The outer wall involute design entrance pre-classifies the feed solids prior to entering the main body of the cyclone. The upper part of the $\operatorname{gMAX}{ }^{\circledR}$ also includes an improved vortex finder and top cover plate liner design. These improvements to the inlet head result in less misplacement of coarse material to the overflow and dramatically increased wear life. This longer wear life for the $\mathrm{gMAX}^{\circledR}$ inlet, combined with premium ceramics in the lower parts of the cyclone, will greatly increase complete cyclone repair frequency. Through the use of CFD analysis, Krebs has designed the $\mathrm{gMAX}^{\circledR}$ cyclone with sharper upper cones followed by longer angled lower cones. This combination maximizes tangential velocity in the upper part of the cyclone. It then provides a long residence time in the critical separation zones in the lower part of the cyclone. This results in a substantially finer separation with fewer fines in the underflow.

The advantages of the $\operatorname{gMAX}{ }^{\circledR}$ inlet are following:

- The partition between the slurry entering the cyclone and the separation chamber of the hydrocyclone has been extended.

- Extra space for incoming slurry with floor to minimize turbulence.

- Classifies the coarse solids before introducing them into the main body of the hydrocyclone.

Krebs Sand Stacking Cyclones are designed for use in solids dewatering applications. The Krebs CycloStack ${ }^{\circledR}$ along with an extended overflow pipe and siphon control assembly attaches to a standard Krebs Cyclone to minimize the moisture content in the cyclone underflow. The attachment provides a low cost way of automatically controlling the dewatering and discharge concentration of the cyclone underflow, allowing direct discharge of the underflow onto a conveyor belt or in a pile. This occurs even with fluctuating feed conditions.

Krebs Sand Stacking Cyclones are reliable, easily installed, and operate automatically. The Krebs CycloStack ${ }^{\circledR}$ consists of a urethane flap which opens when solids are present and allows the solids to discharge while retaining water in the cyclone. With the help of the vacuum which is caused by the siphon created in the overflow pipe, the CycloStack ${ }^{\circledR}$ closes if there are no solids present. The CycloStack $\AA$ improves the cyclone efficiency by constantly adjusting the apex diameter which virtually eliminates plugging and consequently allows attentionfree operation. Figure 5 shows the scheme of dewatering cyclone Krebs gMAX - model gMAX20-SSC. 


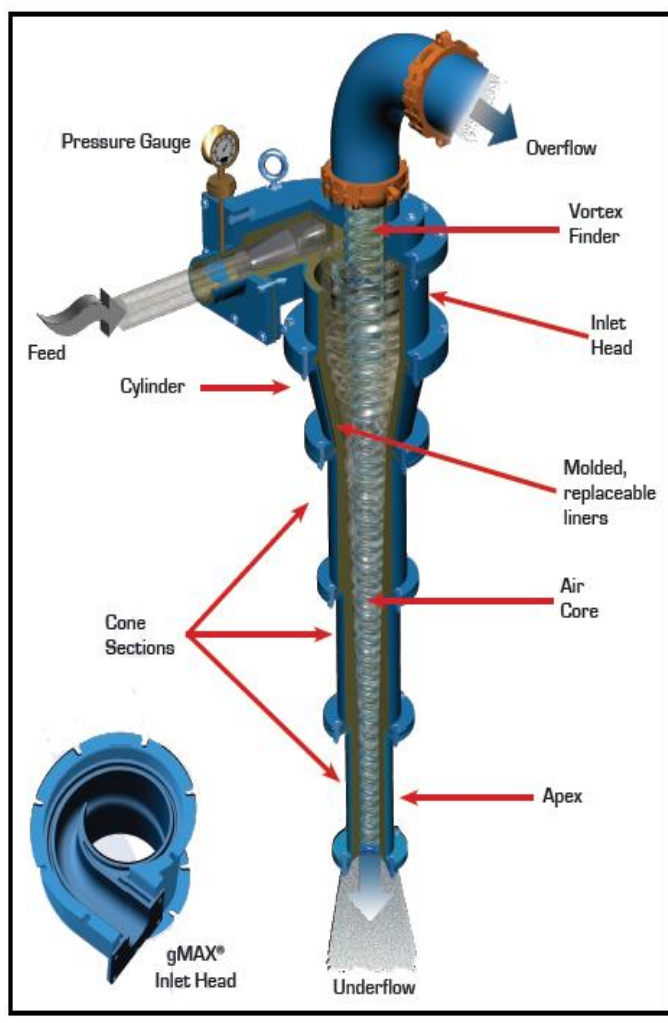

Figure 5. Dewatering cyclone Krebs gMAX - model gMAX20-SSC (325 mm)

The pilot tests with Krebs gMAX - model gMAX20-SSC are carried out at the following conditions: Feed flow rate $-270 \mathrm{~m}^{3} / \mathrm{h}$ and pressure $-\mathrm{P}=1.3$ bar with closed air-bleed valve of overflow pipe.

\section{Results and discussion}

Table 1 shows the chemical analysis of the final technological waste from Lucky Invest Concentrator. Particle size distribution of the tailings sample is shown on the Table 2.

Based on the data from continuous monitoring the technological tailings parameters are determined (Table 3). The flotation tails is relatively fine product $-85 \%$ below $0.200 \mathrm{~mm}$. The tailings slurry capacity is $270 \mathrm{~m}^{3} / \mathrm{h}$ at $18 \mathrm{Wt} \%$ solids.
Table 1. Chemical analysis

\begin{tabular}{|c|c|}
\hline Grades & $\%$ \\
\hline $\mathrm{SiO}_{2}$ & 52.62 \\
\hline $\mathrm{Al}_{2} \mathrm{O}_{3}$ & 8.02 \\
\hline $\mathrm{Fe}_{2} \mathrm{O}_{3}$ & 7.64 \\
\hline $\mathrm{TiO}_{2}$ & 0.40 \\
\hline $\mathrm{Cu}$ & 0.02 \\
\hline $\mathrm{Zn}$ & 0.41 \\
\hline $\mathrm{Pb}$ & 0.22 \\
\hline $\mathrm{CaO}$ & 10.50 \\
\hline $\mathrm{MgO}$ & 1.76 \\
\hline $\mathrm{MnO}$ & 4.07 \\
\hline $\mathrm{K}_{2} \mathrm{O}$ & 1.72 \\
\hline $\mathrm{Na}_{2} \mathrm{O}$ & 0.60 \\
\hline $\mathrm{P}_{2} \mathrm{O}_{5}$ & 0.06 \\
\hline $\mathrm{SO}_{3}$ & 4.98 \\
\hline Loss of ignition & 6.89 \\
\hline
\end{tabular}

Table 2. Particle size distribution

\begin{tabular}{|c|c|}
\hline $\begin{array}{c}\text { Particle size, } \\
\mu \mathrm{m}\end{array}$ & $\begin{array}{c}\text { Yield, } \\
\%\end{array}$ \\
\hline+400 & 8.20 \\
\hline$-400+200$ & 7.20 \\
\hline$-200+100$ & 24.80 \\
\hline$-100+63$ & 7.70 \\
\hline$-63+56$ & 3.20 \\
\hline$-56+45$ & 4.30 \\
\hline$-45+32$ & 6.60 \\
\hline$-32+20$ & 7.90 \\
\hline$-20+10$ & 10.20 \\
\hline$-10+7$ & 4.90 \\
\hline$-7+5$ & 4.30 \\
\hline$-5+2$ & 8.00 \\
\hline-2 & 2.70 \\
\hline Total & 100.00 \\
\hline
\end{tabular}

Table 4 shows the results of laboratory tests with Linatex HK40 at three different positions of siphon control valve - closed, 30 and $50 \%$ opened air-bleed valve of overflow pipe. 
Table 3. Technological tailings parameters

\begin{tabular}{|c|c|c|}
\hline Solids Mass Flow & $\mathrm{t} / \mathrm{h}$ & 54.66 \\
\hline Water Volume Flow & $\mathrm{m}^{3} / \mathrm{h}$ & 249 \\
\hline Slurry Mass Flow & $\mathrm{t} / \mathrm{h}$ & 303.66 \\
\hline Solid SG & $\mathrm{g} / \mathrm{cm}^{3}$ & 2.6 \\
\hline Slurry SG & $\mathrm{g} / \mathrm{cm}^{3}$ & 1.125 \\
\hline Solids & $\mathrm{Wt} \%$ & 18.00 \\
\hline Solids & $\mathrm{Vol} \%$ & 7.79 \\
\hline Slurry & $\mathrm{m}^{3} / \mathrm{h}$ & 270.0 \\
\hline
\end{tabular}

Table 4. Laboratory tests - Particle size distribution of the feed slurry and the obtained products

\begin{tabular}{|c|c|c|c|c|c|c|c|}
\hline \multirow{3}{*}{$\begin{array}{c}\text { Particle } \\
\text { size, } \\
\mu \mathrm{m}\end{array}$} & \multirow[t]{2}{*}{ Feed } & \multicolumn{2}{|c|}{$\begin{array}{c}\text { Closed air-bleed } \\
\text { valve }\end{array}$} & \multicolumn{2}{|c|}{$\begin{array}{l}30 \% \text { opened air- } \\
\text { bleed valve }\end{array}$} & \multicolumn{2}{|c|}{$\begin{array}{l}50 \% \text { opened air- } \\
\text { bleed valve }\end{array}$} \\
\hline & & Overflow & Underflow & Overflow & Underflow & Overflow & Underflow \\
\hline & $\begin{array}{c}\text { Yield, } \\
\%\end{array}$ & $\begin{array}{c}\text { Yield, } \\
\%\end{array}$ & $\begin{array}{c}\text { Yield, } \\
\%\end{array}$ & $\begin{array}{c}\text { Yield, } \\
\%\end{array}$ & $\begin{array}{c}\text { Yield, } \\
\%\end{array}$ & $\begin{array}{l}\text { Yield, } \\
\%\end{array}$ & $\begin{array}{c}\text { Yield, } \\
\%\end{array}$ \\
\hline+160 & 15.20 & 0.00 & 31.00 & 0.00 & 21.30 & 0.00 & 20.80 \\
\hline$-160+100$ & 19.60 & 0.00 & 47.80 & 0.00 & 19.10 & 0.00 & 21.00 \\
\hline$-100+63$ & 15.80 & 0.00 & 13.20 & 0.00 & 19.50 & 0.00 & 19.30 \\
\hline$-63+56$ & 9.20 & 0.20 & 3.30 & 2.90 & 11.50 & 2.10 & 9.20 \\
\hline$-56+45$ & 3.20 & 0.80 & 1.10 & 4.80 & 7.40 & 3.60 & 4.50 \\
\hline$-45+32$ & 3.30 & 3.40 & 1.10 & 6.10 & 6.20 & 6.10 & 7.00 \\
\hline$-32+20$ & 7.00 & 11.30 & 0.90 & 12.70 & 4.90 & 13.20 & 6.10 \\
\hline$-20+10$ & 5.70 & 18.00 & 0.60 & 16.70 & 4.00 & 17.10 & 5.10 \\
\hline$-10+5$ & 9.00 & 22.10 & 0.60 & 19.40 & 3.10 & 19.90 & 3.50 \\
\hline-5 & 12.00 & 44.20 & 0.40 & 37.40 & 3.00 & 38.00 & 3.50 \\
\hline Total & 100.00 & 100.00 & 100.00 & 100.00 & 100.00 & 100.00 & 100.00 \\
\hline
\end{tabular}

The laboratory experimental results clearly indicate the particle size cutpoint of separator Linatex HK40. It was achieved $56 \mu \mathrm{m}$ cutpoint at closed air-bleed valve of overflow pipe.

Figure 6 shows the mass balance from laboratory tests with Linatex HK40 at different positions of siphon control valve: closed air-bleed valve of overflow pipe; $30 \%$ and $50 \%$ opened air-bleed valve of overflow pipe.

Experimental results show that a decrease of the vacuum in the separator Linatex HK40 is reduced the solids content in the overflow from 8.10 to $6.38 \mathrm{Wt} \%$. In the same time a part of the fine particles and water pass into the underflow in which the moisture content increases. It has been shown that Linatex HK40 achieves high solids content $-66 \mathrm{Wt} \%$ into the lower product in comparison with conventional hydrocyclones. Based on the laboratory test results were performed pilot tests with closed air-bleed valve of overflow pipe.

Table 5 shows the experimental results of pilot test with Linatex HK80. 


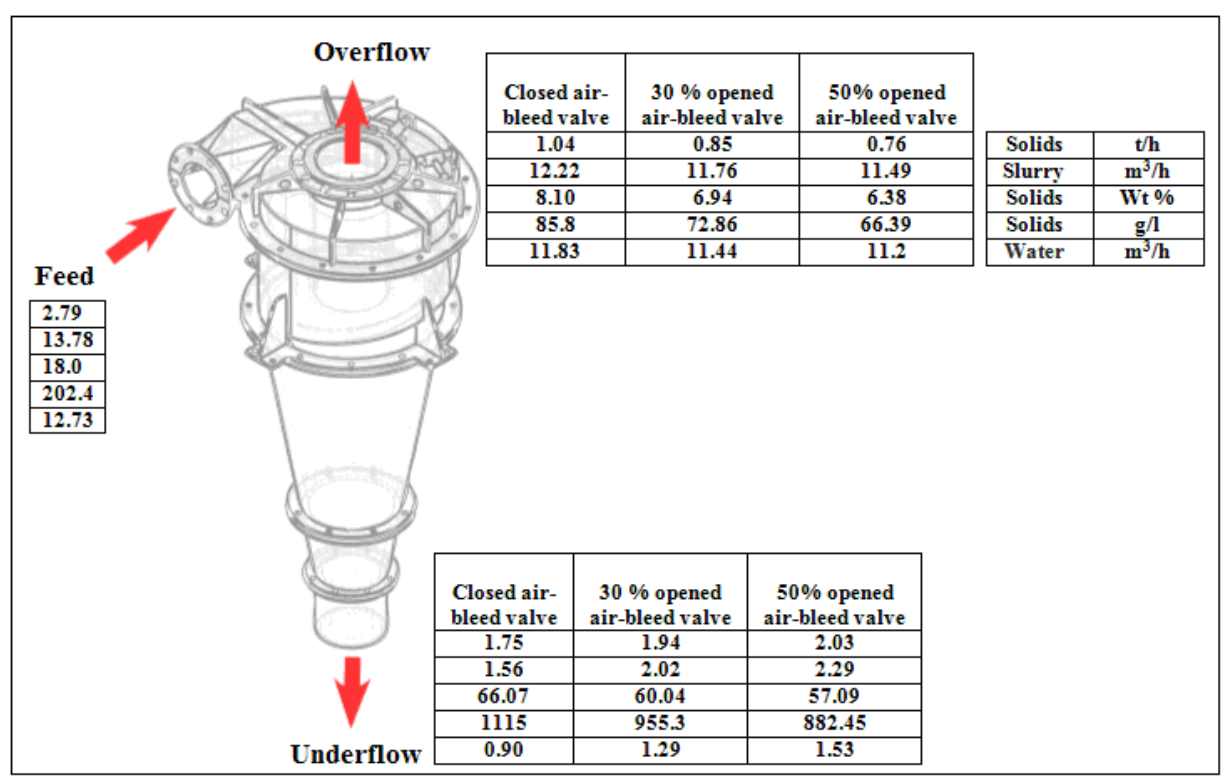

Figure 6. Laboratory test mass balance

Table 5. Linatex HK80 pilot test - feed, overflow and underflow particle size distribution

\begin{tabular}{|c|c|c|c|}
\hline \multirow{2}{*}{$\begin{array}{c}\text { Particle } \\
\text { size, } \\
\mu \mathrm{m}\end{array}$} & Feed & Overflow & Underflow \\
\hline & $\begin{array}{c}\text { Yield, } \\
\%\end{array}$ & $\begin{array}{c}\text { Yield, } \\
\%\end{array}$ & $\begin{array}{c}\text { Yield, } \\
\%\end{array}$ \\
\hline+160 & 15.00 & 0.00 & 26.90 \\
\hline$-160+100$ & 12.90 & 0.00 & 22.20 \\
\hline$-100+63$ & 12.10 & 0.00 & 22.00 \\
\hline$-63+56$ & 8.00 & 2.80 & 11.50 \\
\hline$-56+45$ & 3.10 & 3.10 & 3.00 \\
\hline$-45+32$ & 4.10 & 5.10 & 3.90 \\
\hline$-32+20$ & 7.30 & 10.10 & 4.00 \\
\hline$-20+10$ & 8.20 & 15.00 & 3.00 \\
\hline$-10+5$ & 10.30 & 21.10 & 1.70 \\
\hline-5 & 19.00 & 42.80 & 1.80 \\
\hline Total & 100.00 & 100.00 & 100.00 \\
\hline
\end{tabular}

The experimental results show that the increase of separator hydraulic capacity $\left(\mathrm{m}^{3} / \mathrm{h}\right)$ leads to the change of particle size cutpoint from $56 \mu \mathrm{m}$ to $63 \mu \mathrm{m}$.

Figure 7 shows the pilot test mass balance with Linatex HK80 - closed air-bleed valve of overflow pipe.

The mass balance summarizes the experimental results obtained from the pilot test. The content of the solid phase in the overflow is $8.62 \%$, while into the underflow $65.12 \%$. These obtained values confirm the laboratory tests experimental results.

\section{Mathematical modeling of dewater- ing separator Linatex HK125}

Based on the laboratory and pilot tests results mathematical modeling of the process on dewatering process of technological waste was conducted. For dewatering of $270 \mathrm{~m}^{3} / \mathrm{h}$ technological waste will be required two separators Linatex HK 125 with 1.3 bar operational pressure. Mass balance test is given on the Figure 8. 


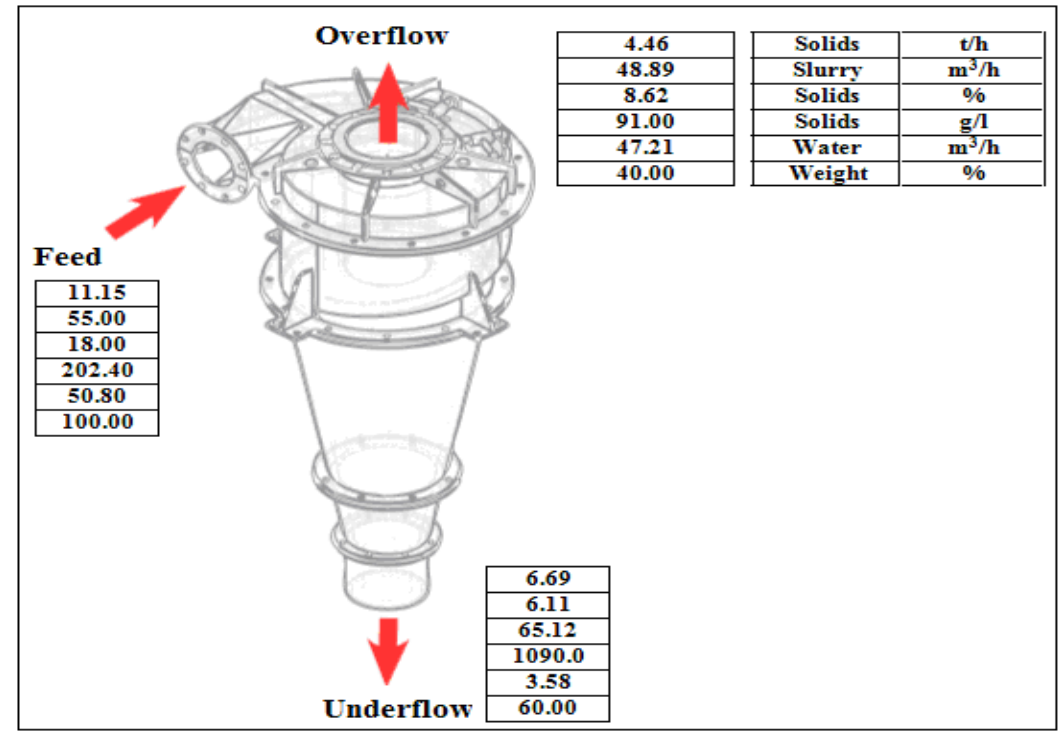

Figure 7. Pilot test mass balance with Linatex HK80

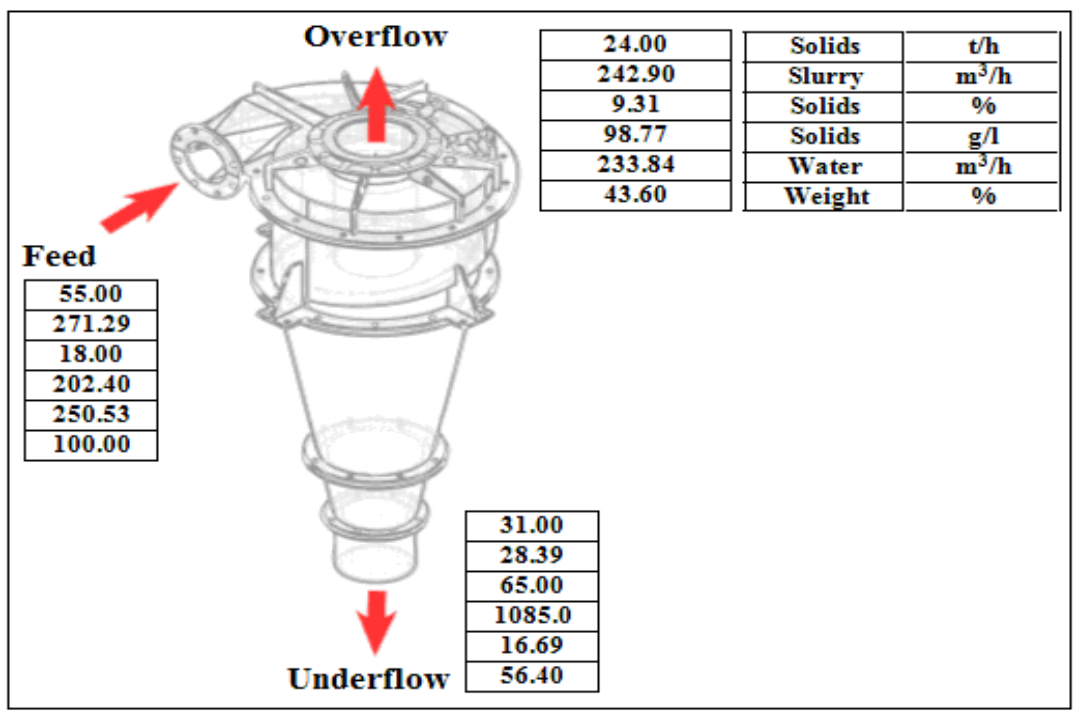

Figure 8. Mass balance test with Linatex HK 125

The following values are obtained: $65 \%$ solids content into the underflow and $9.31 \%$ solids in the overflow. The experimental results from laboratory and pilot tests and mathematical modeling show that Linatex HK separators could be used for the dewatering of the final technological waste. Water content is reduced of almost 2.5 times - from $82 \%$ in technological waste to $35 \%$ into the underflow. This result proves the technological possibilities of separators Linatex HK.

Table 6 shows the experimental results (feed, overflow and underflow particle size distribution) of pilot test with dewatering cyclone Krebs gMAX20-SSC. 
Table 6. Krebs gMAX20-SSC pilot test feed, overflow and underflow particle size distribution

\begin{tabular}{|c|c|c|c|}
\hline $\begin{array}{c}\text { Particle } \\
\text { size, } \\
\boldsymbol{\mu m}\end{array}$ & $\begin{array}{c}\text { Feed } \\
\text { Yield, } \\
\mathbf{\%}\end{array}$ & $\begin{array}{c}\text { Yield, } \\
\mathbf{\%}\end{array}$ & $\begin{array}{c}\text { Yield, } \\
\mathbf{\%}\end{array}$ \\
\hline+315 & 8.20 & 0.00 & 14.02 \\
\hline$-315+250$ & 7.20 & 0.00 & 12.31 \\
\hline$-250+160$ & 11.00 & 0.00 & 19.30 \\
\hline$-160+100$ & 13.80 & 0.06 & 23.04 \\
\hline$-100+63$ & 7.70 & 1.08 & 12.39 \\
\hline$-63+56$ & 3.20 & 0.91 & 4.83 \\
\hline$-56+45$ & 4.30 & 3.18 & 5.10 \\
\hline$-45+32$ & 6.60 & 10.16 & 4.07 \\
\hline$-32+20$ & 7.90 & 16.24 & 1.98 \\
\hline$-20+10$ & 10.20 & 22.84 & 1.24 \\
\hline$-10+5$ & 9.20 & 23.62 & 0.89 \\
\hline-5 & 10.70 & 14.22 & 0.83 \\
\hline Total & 100.00 & 100.00 & 100.00 \\
\hline
\end{tabular}

The particle size cutpoint of dewatering process of technological tailings using Krebs gMAX20-SSC is $63 \mu \mathrm{m}$. The cyclone realizes the sharper particle separation at high capacity.

Pilot test mass balance with dewatering cyclone Krebs gMAX at closed air-bleed valve of overflow pipe is shown in Figure 9.

The pilot test results clearly demonstrate the new performance standard for dewatering technology. The following values are obtained: $75 \%$ solids content into the underflow and $8.69 \%$ solids in the overflow. The cyclone overflow will pass to the second dewatering stage.

This result shows the potential of new gMAX modification for solid dewatering application. The solids content of underflow is increased more than 4 times - from $18 \%$ in technological waste to $75 \%$ into the underflow.

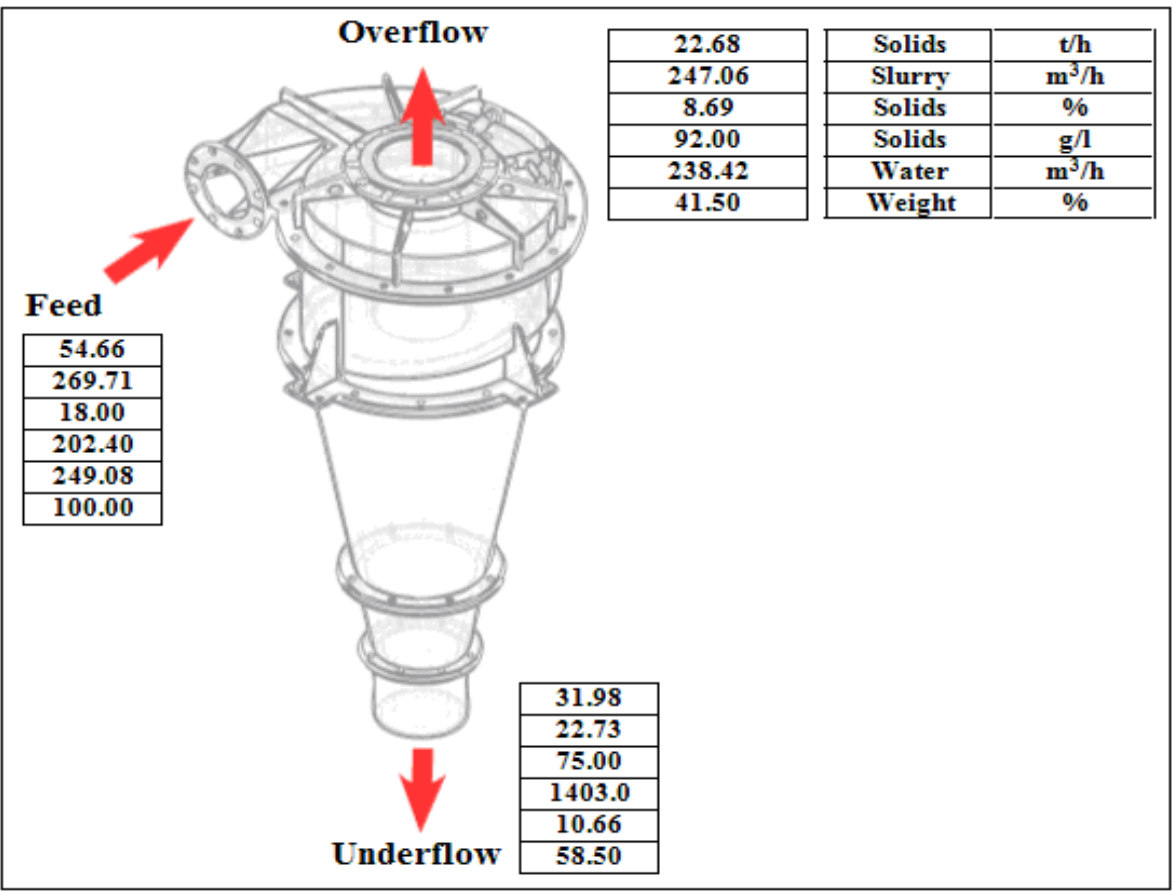

Figure 9. Mass balance test with KREBS gMAX20-SSC 


\section{Conclusions}

The final technological tails of Lucky Invest Concentrator are characterized. The technological tailings parameters are determined. The laboratory and pilot tests experimental results show that new cyclone modifications have a potential in dewatering technology of flotation tailings. The solids content of cyclone underflow is increased more than 4 times - from $18 \%$ in technological waste to $75 \%$ into the underflow at $63 \mu \mathrm{m}$ particle size cutpoint of dewatering process. It appears that dewatering cyclones can be an approach on new tailings pond elimination technology.

\section{References}

[1] Benzaazoua, M., Bussière, B., Demers, I., Aubertin, M, Fried, E., Blier, A. (2008) Integrated mine tailings management by combining environmental desulphurization and cemented paste backfill: Application to mine Doyon. Quebec, Canada, Minerals Engineering, 21 (4), 330-340.

[2] Johnson, S., Wright, A. (2003) Mine void water resource issues in Western Australia: Western Australia, Water and Rivers Commission. Hydrogeological Record Series, Report HG 9, 1-93.

[3] Lottermoser, B. (2007) Mine wastes: characterization, treatment and environmental impacts. Springer, 304.

[4] De Andrade Lima, P., Bernardez, A., Barbosa, D. (2007) Characterization and treatment of artisanal gold mine tailings. Journal of Hazardous Materials, 150 (3), 747-753.

[5] Aubertin, M., Bussire, B., Bernier, L. (2993) Environnement et gestion des résidus miniers. (On $\mathrm{CD}$ ). Les Presses Internationales Polytechnique, École
Polytechnique de Montréal, Québec, Canada.

[6] Rico, M., Benito, G., Salgueiro, R., Díez-Herrero, A., Pereira, G. (2008) Reported tailings dam failures: A review of the European incidents in the worldwide context. Journal of Hazardous Materials, 152 (2), 846-852.

[7] WISE 2007. World Information Service on Energy, Chronology of major tailings dam failures. Available online at: www.wise-uranium.org/mdaf.html.

[8] Verburg, R. (2002) Paste technology for disposal of acid-generating tailings. Mining Environmental Management, 10 (8), 14-18.

[9] Driussi, C., Jansz, J. (2006) Technological options for waste minimization in the mining industry. Journal of Cleaner Production, 14 (8), 682-688.

[10] Bussire, B. (2007) Colloquium 2004: Hydro-geotechnical properties of hard rock tailings from metal mines and emerging geoenvironmental disposal approaches. J. Can. Geotech, 44 (9), 1019-1052.

[11] Ritcey, M. (2005) Tailings management in gold plants. Hydrometallurgy, 78 (12), 3-20.

[12] Yilmaz, E. (2011) Advances in reducing large volumes of environ-mentally harmful mine waste rocks and tailings. Gospodarka Surowcami Mineralnymi, 27 (2), 90-110.

[13] Kwak, M., James, D., Klein, K. (2005) Flow behaviour of tailings paste for surface disposal. International Journal of Mineral Processing, 77 (3), 139-153.

[14] http://www.weirminerals.com

[15] http://www.flsmidth.com 